\title{
Dependence of Vehicle Collisions with Roe Deer on Spatial and Temporal Factors in Lithuania
}

\author{
Lina Galinskaite*, Gytautas Ignatavičius, Vaidotas Valskys \\ Life Sciences Center, Institute of Biosciences, Vilnius University, Vilnius, Lithuania
}

Received 04 February 2020; accepted 31 March 2020

\begin{abstract}
Rising road densities, vehicle speeds limits and traffic volumes, combined with recent growth in the population density of various deer species, have increased the risk of DVCs across the world, causing a great deal of animal suffering, traffic safety problems and socio-economic costs. Object of this investigation was to find out collisions trend with roe deer (Capreolus capreolus) in Lithuania. The aim of our study was to determine where in Lithuania accidents occure more frequently and evaluate these accidents in time. In 2013-2017 number of AVCs in Lithuania was recorded more then 12011 times, over half of 7155 occur with roe deer. The temporality of accidents was studied under three scales - daily, weekly and seasonal. Daily peaks start at 7:00 (8.75\%), 8:00 (6.08\%). Evening peaks, start at 17:00 $(7.71 \%)$, other at 22:00 (10.64\%) hours. Week collisions with roe deer increase on Friday $14.9 \%$. The risk of collision with roe deer varies over the year - the majority of crashes occur in May $14.7 \%$ and November $10.7 \%$. In spatial study localization of collision data with ArcGIS 10.3. It was found that road surrounding landscape dominated by agricultural land collisions occurred at a maximum of $29.77 \% .19 .10 \%$ collisions were recorded in the forest area. In built-up areas $11.85 \%$. Analysis of these trends allow to simulate and predict when and where the highest risk of DVCs occurs. In conclusion, this could give valuable information and constitute a manageable tool for the road managers, planners, scientist, wildlife conservationist who are interested in these type of accidents in regions of Lithuania.
\end{abstract}

Keywords: roe deer-vehicle collisions, hot spots, temporal fluctuations, landscape.

\section{Introduction}

Traffic infrastructure and its traffic flows has rapidly developed in recent decades. This development brings benefits to society, but on the other hand has many negative impacts on the environment. Among the most negative effects of traffic infrastructure and its traffic flows are direct taking of land and transformation of natural biotopes migration impediment, fragmentation of natural biotopes. But the most significant impacts of road traffic is direct mortality of free-ranging animals due to vehicle collisions (Kušta et al., 2016). Many species of free-ranging animals are killed on roads. However, large mammals, mainly ungulates, are the main group involved in the conflict and most AVCs are caused by red deer (Cervus elaphus), roe deer (Capreolus capreolus), fallow deer (Dama dama), and moose (Alces alces) (Bartonicka et al., 2018). Various measures to mitigate have been tested but only exclusion fencing and roadside clearing have proven efficient and become standard in road management for traffic safety. Results of small-scale experiments have suggested that road fencing may locally reduce the risk by $80 \%$, while clearing the roadside of cover and forage attractive to ungulates may result in a $20 \%$ (Seiler, 2005).

WVC is considered to be a significant trafic safety issue both in Lithuania and all over the world (Balčiauskas \& Jasiulionis, 2012; Gunson et al., 2009). The main reason why there are so many studies dealing with UVCs is the result of collisions with these animals (Kušta et al., 2016). An UVC usually leads to major property damage and it may result in human injury or casualty. Indeed, in Europe (excluding Russia) close to half a million deer are estimated to be hit by vehicles every year, leading to over 300 human fatalities, 30.000 human injuries and with damage to property exceeding \$1 billion (Pokorny, 2006). Total costs of DVC in Slovenia are assessed atc. 15 million Euros per year. Costs of ungulate-vehicle collisions in Finland are estimated at 163 million Euros per annum, in Sweden and France at around 100 million Euros (per annum) and in Germany at 447 million Euros, but it is difficult to interpret such global estimates (Langbein et al., 2011).

In Europe, roe deer (Capreolus capreolus) is medium-sized mammal species killed in traffic, and the number of accidents seems to increase (Madsen et al., 2002). In Lithuania accidents involving roe deer represent a major part of the WVC (Balčiauskas, 2009; Oškinis et al., 2013). People are rarely killed in collisions with roe deer but they often experience various degrees of physical and other health damage. For animal thease accidents are usually fatal. Roe

*Corresponding author. E-mail: lina.galinskaite@gmc.stud.vu.lt

\section{Copyright (C) 2020 The Author(s). Published by VGTU Press}

This is an Open Access article distributed under the terms of the Creative Commons Attribution License (http://creativecommons.org/licenses/by/4.0/), which permits unrestricted use, distribution, and reproduction in any medium, provided the original author and source are credited. 
deer show bimodal crepuscular activity peaks and space use varies between seasons. Analyses of temporal patterns in roe deer-vehicle collision occurrence have found visual similarities of temporal variation in collision incidence with the activity rhythm and seasonal variation in movement activity (Kämmerle et al., 2017). The main objective of this study to use collisions with roe deer reported to traffic authorities in the Lithuania to characterize their spatial and temporal (daily, weekly and monthly) distribution.

\section{Materials and methods}

An analysis of vehicle collision with roe deer trends was carried out throughout the territory of Lithuania. Total area of the country is $65.300 \mathrm{sq} . \mathrm{km}$. Lithuania is in the temperate climate zone and the sub-region of Atlantic-European continental mixed and broad-leaved forests. Forest area (\% of land area) consists of $34.83 \%$. Agricultural land $47.16 \%$, arable land in Lithuania was reported at 34.2\% (https://radingeconomics.com/lithuania/land-area-sq-km-wbdata.html). The Lithuanian road network consists of main roads $(1,750.710 \mathrm{~km})$, national roads 4,927.684 km, regional roads 14,559.243 km. Accorring to Lithuanian Road Administration under the Ministry of Transport and Communications in 2019 road network consisted of total 21,237.637 km roads (Lithuanian Road Administration under the Ministry of Transport and Communications, n.d.). Since 1994, the average road traffic density has increased by 15-20\% each year (International Business Publications, n.d.).

Data on vehicle collisions with animals for the period of 2013-2017 were obtained from the Lithuanian Road Police. Each accident was recorded and described by the date, hour, location (geographic coordinates) and species of animal (wild and domestic species). A total of 12011 WVCs cases were recorded during the study period. After selecting only roe deer records totall of 7155 collisons was observed. For spatial analysis, these selected accidents were transmitted to the GIS database according to the collision coordinates based on the LKS 94 coordinate system. Some coordinates were removed from the data set, because they slipt outside the study area. After eliminating those records, 6112 accident data was left and used for spatial GIS analysis.

Basic statistics of temporal (daily, weekly and monthly) analysis was carry out with Microsoft Excel (Windows 10) using radar charts. All registered accidents were classified according to selected species, month and time of the day when collision occurred. In spatial analyses each collision record was analysed in a manner of distance to selected elements of land use (agriculture land, meadowns and pastures, forest, built-up areas). Given incident points weighted features (in this case points) creates a statistically significant cold and hor spots in a map. The analysis of hot spot vehicle collisions with wildlife is a an effective way to determinate witch landscape (land-use) factors are the most important for the cause of such collisions (Snow et al., 2014).

\section{Results}

Crashes involving roe deer did not occur evenly throughout the year. Significantly more collisions occurring in the middle of year, May (14.6\%) with a higher risk of accidents at the end of the year, during November $(10.6 \%)$, December $(9.2 \%)$ October $(9.1 \%)$. There was only a weak correlation between the total number of accidents and collisions with roe deer $(r=0.27)$. The total percentage of car accidents reaches a peak in December $(10.2 \%)$ and August (10.1\%). It can be assumed that fluctuations in traffic intensity do not have a significant impact on accidents involving roe deer in Lithuania. Distribution of roe deer vehicle collisions for different months is presented in Figure 1.

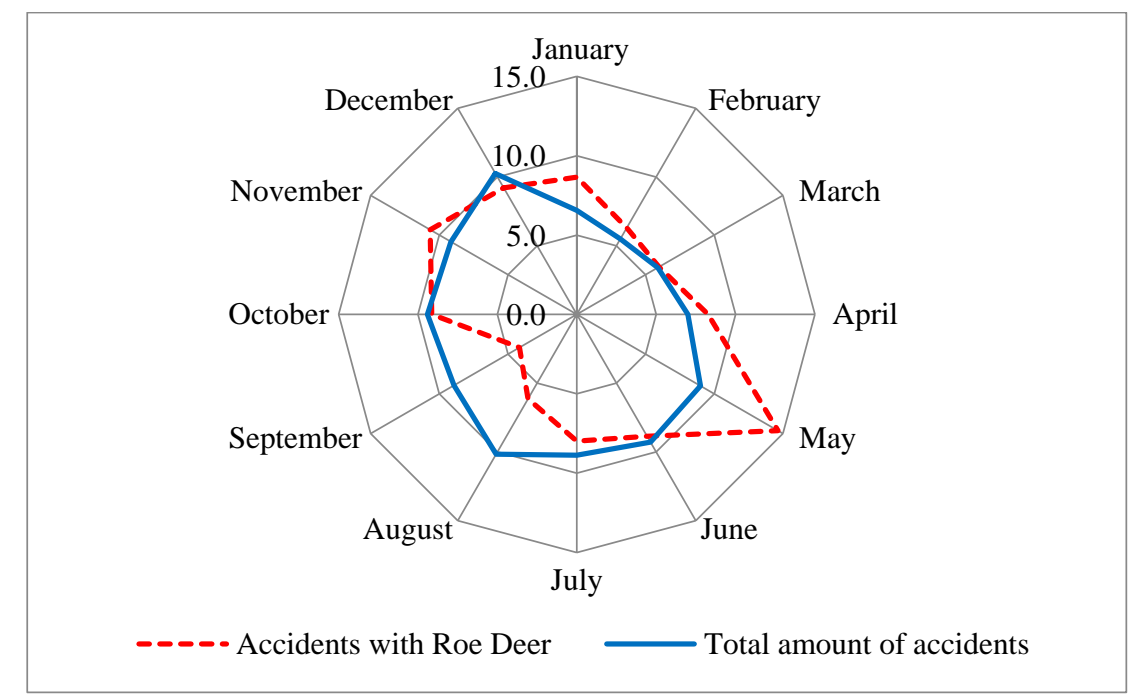

Figure 1 . Monthly distribution of vehicle collision with roe deer and total weekly car accidents in Lithuania for the period 2013-2017 (\%) $(\mathrm{n}=7155)$ 
On a daily basis, the highest incidence of roe deer collision occurs between 07:00-08:00 a.m.,16:00-17:00 p.m. and 09:00-10:00 p.m., exhibiting a strong bimodal pattern. In fact, the early morning and late evening hours constitute $8.75 \%$ and $10.64 \%$, respectively, roe deer collision. Period between 09:00 a.m and 15:00 p.m. seems to be a period of minimum risk for collision with roe deer in Lihuania. Also we did have the total number of car accidents in Lithuania for separate months in 2013 and 2017, which reflect daily changes of traffic intensity. Weak correlation $(r=0.22)$ was found between the hourly fluctuation in the number of accidents during the day and the number of car collisions with roe deer. Number of total accidents increased in the morning (07:00 hours) and evening (17:00 hours) peak hours. Increases in roe deer collisions with cars were recorded when total number of accidents had reached its peak (Figure 2).

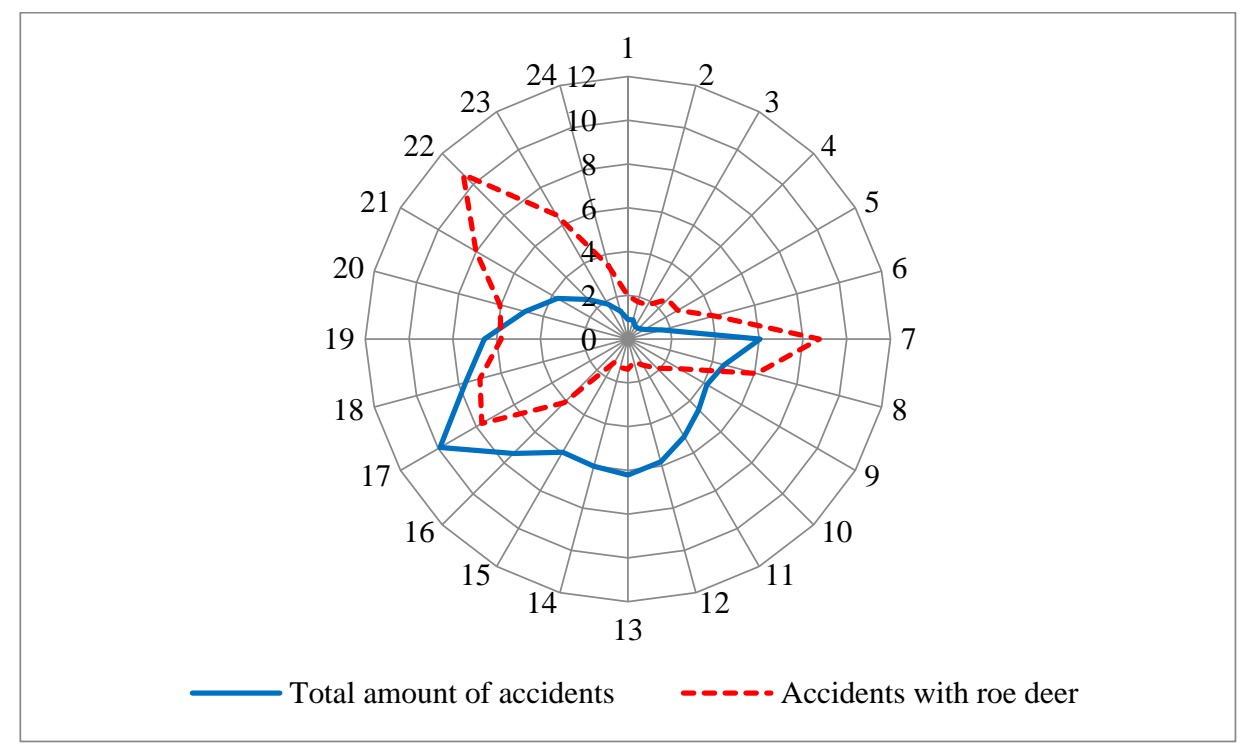

Figure 2. Hourly distribution patterns of road accidents for roe deer and distribution of total number of accidents in Lithuania in period of 2013-2017 (\%) $(\mathrm{n}=7155)$

The weekly pattern of collisions with roe deer increases slightly on Fridays (14.9\%) and on Saturday (14.5\%). At the begining of the week Monday (13.9\%) Tuesday (13.8\%) collisions occure less then at the end of the week. Positive correlation $(\mathrm{r}=0.53)$ was found between the total number of accidents during the week and the number of car collisions with roe deer. Total accidents increased on Friday (16.4\%), and decrees during Saturday (13.8\%) and Sunday (11.8\%) (Figure 3).

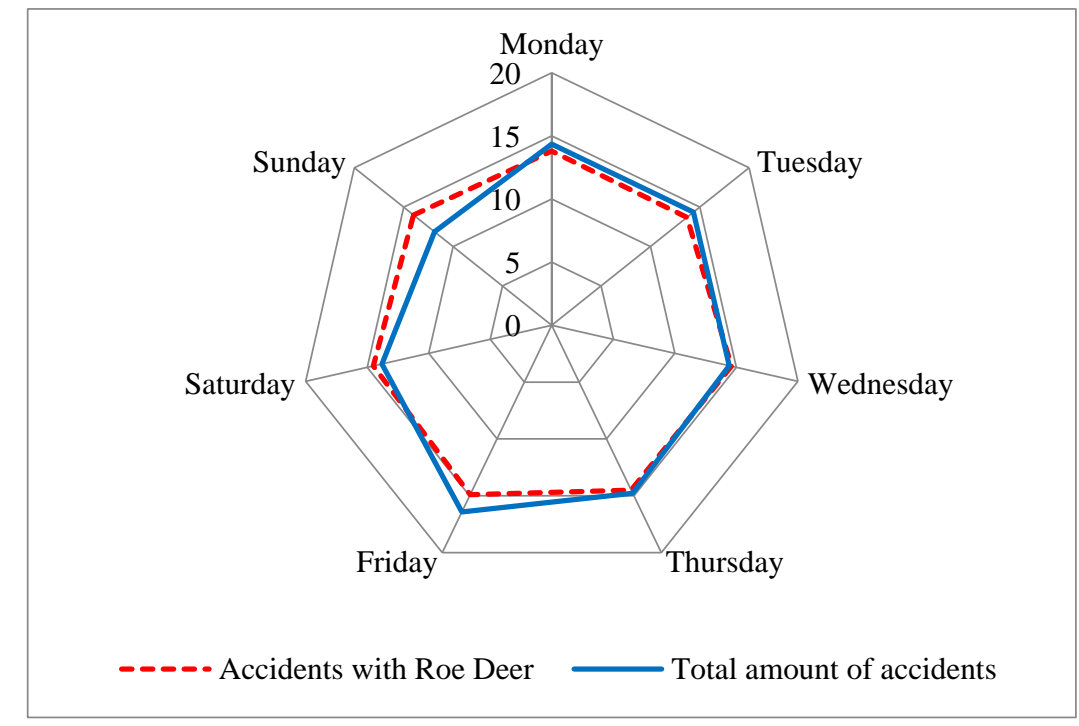

Figure 3. Total weekly car accidents and collisions with vehicles involving roe deer in Lithuania for the period 2013-2017 (\%) $(\mathrm{n}=7155)$ 
We mapped the location of all the traffic accidents with roe deer from 2014 to 2017 wich occure in the Lithuania with ArcGIS 10.3®. Then after near analysis and Optimyse hot spot analyses we got map where vehicle collision occure more often. These results can be seen in Figure 4. Also it was important to determine the kind of land cover that exists around the location of roe deer collisions in Lithuania. It was found out in what landscape surrounding roads collisions occure most. $29.74 \%$ of collision occure in agriculture land. In forest area $19.10 \%$. Area with buildings $11.85 \%$, meadowns and pastures $-5 \%$. Built-up areas 3.03\%. These results can be seen in Figure 5.

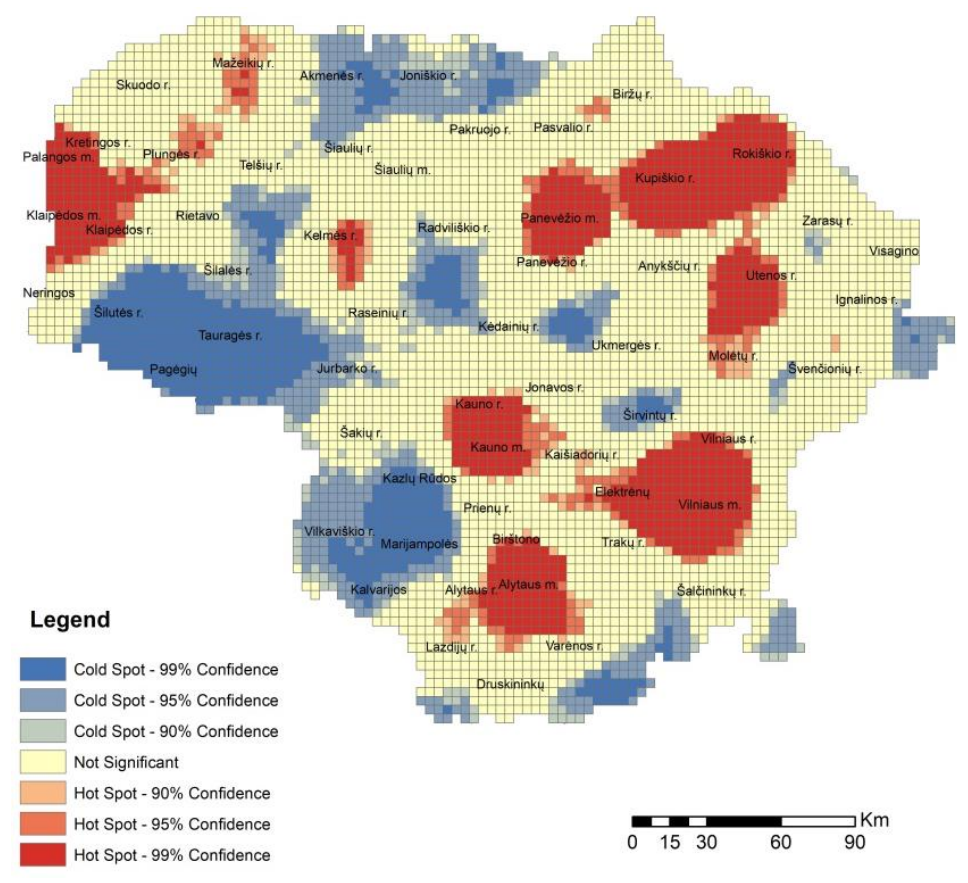

Figure 4. The total of collisions with roe deer hot spot distribution in Lithuania 2014-2017

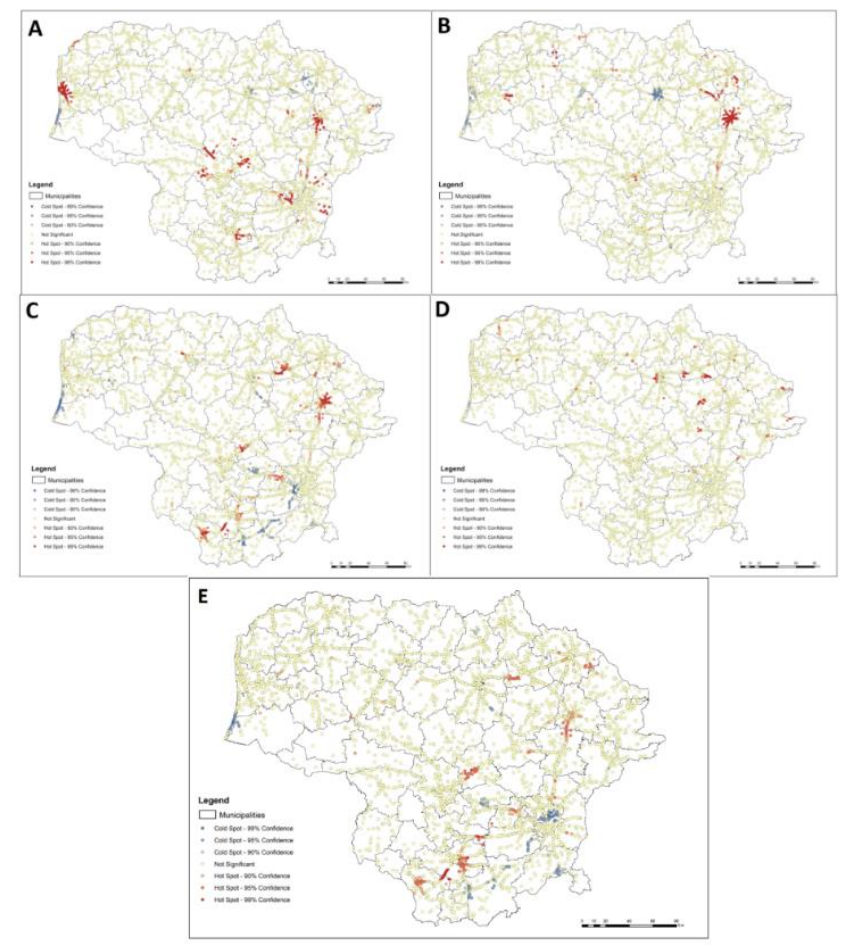

Figure 5. The total of collisions hot spots distribution by main types of land use. a) hot spot analysis of collsions that depend on agricultural land; b) hot spot analysis of collsions that depend on forests; c) area with buildings; d) hot spot analysis of collsions that depend on meadows and pastures; e) hot spot analysis of collsions that depend on built-up areas 


\section{Conclusions}

It is clear from the overall, although some DVCs occur throughout the year, the distribution among months is nonrandom. The most prominent overall peak in accidents is shown to occur during May (14.6\%), with a secondary peak from November $(10.6 \%)$, through to December $(9.2 \%)$. The same monthly paterns of roe deer collision was found in other European countries (Langbein, 2007; De Vries, 2015; Diaz-Varela et al., 2011; Lagos et al., 2012, RodríguezMorales et al., 2013; Bartonicka et al., 2018).

The spring period coincides with roe deer's parturition. From April to June the fawns born on the former year and that still live within the family unit, abandon the group and wander erratically in search for a free area to settle. This occurs more frequently in April, when mothers expel fawns massively to bring up the future offspring (DiazVarela et al., 2011). This situation will likely drive young roe deer to cross some roads. Therefore, one-year-old roe deers are expected to have a high level of involvement in traffic collisions in the spring. On the other hand, while newly born fawns lay concealed by vegetation waiting for their mother's milk, their mothers cover the territory searching for food (Mateos-Quesada \& Carranza, 2000). Females walk longer distances than those not having offspring to get food with additional nutrients that improve their milk quality. Other authors, however, found smaller home ranges for lactating mothers than for females lacking fawns (Bongi et al., 2008).

The high accident rate from July to mid-August may be related to the rutting period, which takes place during those months (Rodríguez-Morales et al., 2013). Bucks increase displacements within their home range, looking for females to mate (Lamberti et al., 2006), thus being more prone to traffic collisions. Likewise, adult females might increase the length and intensity of daily movements during heat, even beyond their home range (Richard et al., 2008). A secondary peak in DVCs for roe deer also occurs when the day length shortens. And arising foraging movements and local migrations (Wahlström \& Liberg, 1995).

Apparently roe deer exhibits a number of daily activity-bouts depending on season, habitat and disturbance (Cederlund, 1989) but activity (e.g. foraging, translocation) may be shifted or skipped if inevitable. Collisions with roe deer occurred at any time of the day (Figure 2). Time from 2013-2017 showed two evening peaks one at 17:00 and and one at 22:00 hours that can be linked to roe deer activity cycles. Roe deer are more active after dark when the two peaks were observed: one in the evening and one at night (De Vries, 2015). They tend to migrate and forage in the dark and when this coincides with morning or evening increases in traffic an increase in the number of collisions with vehicles is seen (Putman, 1997). The morning peak reach at 07:00 a.m. when light is still poor, and it is difficult for motorist to observe the road and animal road-crossing behavior. Daily pattern of accidents is coherent with roe deer's habits, as this species stays active both day and night, combining several activity and resting periods (Seiler, 2004).

There was limited information in reviewed roe deer literature about DVA pattern regarding weekdays (Steiner et al., 2014). However, Motales et al. (2013), Morelle et al. (2013) pointed out Saturday and Friday as the days with the highest risk of roe deer accidents. Hothorn et al. (2015) find the same pattern that more accidents occurred during Friday and Saturday. Similar pattern was found in Lithuania with the highest risk peak in Friday (14.9\%) and Saturday (14.5\%). This pattern can be explained by car traffic who is also higher due to people driving more outside the city. Yet collisions with the roe deer depending on day of week should be analyzed in more.

Spatial analyses of accidents showed that roe deer distribution along the Lithuanian road network was not random. Map showed areas with higher risk of DVC's (Figure 4). Land cover are likely to explain this non-random pattern (Gonser et al., 2009). A common belief is that wildlife casualties are likely to occur in highly forested area, but recent papers have demonstrated the role of agricultural land on risk of casualties with deer (Gonser et al., 2009). These habitats are indeed particularly providing both cover and food resources for roee deer (Baleišis et al., 1998). The roe deer is mostly seen at zones between agricultural or grass land and forests, as this offers them the best living conditions. Analyzed data of car collision with roe deer in 2014-2017 in Lithuania showed that these events are mostly recorded near the land used for agriculture land $29.77 \%$, in forest areas occurred in $19.10 \%$, area with buildings $-11.85 \%$, meadowns and pastures $5 \%$ and built-up areas the lowest collision rate was $3.03 \%$.

Various measures to prevent WVC have been recommendet over the years, some have been evaluated, many have been installed, but only very few have showed a noticeable effect. There is no single tool that prevents WVC. Prevention needs a combination of view that target different factors on different scales. Most expensive but also the most effective approach to prevent WVC is to physically separate wildlife and traffic. Research clearly advocates an inclusive fencing system consisting of fences that are adapted in height, strength and meshsize to the behaviour of the target species; escape facilities such as jump-outs; gates or wildlife grids that secure openings in the fence where other roads connect (Seiler et al., 2016).

This study showed that the time of year is very important for the prediction of roe deer collisions. Daily peaks are directly related to the change of lighting during the year and trafic flow. Season and time of day is very important factors for the collisions dynamics. It is hoped that the results from this study will encourage future studies to examine the human-environment interface. Future research could focus on other variables that may impact the location of DVCs. These data may play a critical role in understanding DVCs. 


\section{References}

Balčiauskas, L. (2009). Distribution of species-specific wildlife-vehicle accidents on Lithuanian roads, 2002-2007. Estonian Journal of Ecology, 58, 157-168. https://doi.org/10.3176/eco.2009.3.01

Balčiauskas, L., \& Jasiulionis, M. (2012). Reducing the incidence of mammals on public highways using chemical repellent. The Baltic Journal of Road and Bridge Engineering, 7, 92-97. https://doi.org/10.3846/bjrbe.2012.13

Baleišis, R., Bluzma, P., \& Balčiauskas, L. (1998). Lietuvos kanopiniai žverrys. Asveja.

Bartonicka, T., Andrasik, R., Dula, M., Sedonik, J., \& Bil, M. (2018). Identification of local factors causing clustering of animalvehicle collisions. Journal of Wildlife Management, 82, 940-947. https://doi.org/10.1002/jwmg.21467

Bongi, P., Ciuti, S., Grignolio, S., Del Frate, M., Simi, S., Gandelli, D., \& Apollonio, M. (2008). Anti-predator behaviour, space use and habitat selection in female roe deer during the fawning season in a wolf area. Journal of Zoology, 276, $242-251$. https://doi.org/10.1111/j.1469-7998.2008.00481.x

Cederlund, G. (1989). Activity patterns in moose and roe deer in a north boreal forest. Holarctic Ecology, 12(1), 39-45. https://doi.org/10.1111/j.1600-0587.1989.tb00820.x

De Vries, M. (2015). Road kills of roe deer (Capreolus capreolus) in the Netherlands: assessment of impacts and mitigation measures (MSc Internship report). Copernicus Institute of Sustainable Development, Utrecht University Utrecht.

Diaz-Varela, E., Marey-Perez, M., Vazquez-Gonzalaz, I., \& Alvarez-Lopez, C. (2011). Assessing methods of mitigating wildlifevehicle collisions by accident characterization and spatial analysis. Transportation Research Part D Transport and Environment, 16, 281-287. https://doi.org/10.1016/j.trd.2011.01.002

Gonser, R. A., Jensen, R. R., \& Wolf, S. E. (2009).The spatial ecology of deer-vehicle collisions. Applied Geography, $29,527-532$. https://doi.org/10.1016/j.apgeog.2008.11.005

Gunson, K. E., Clevenger, A. P., Ford A. T., Bissonette, J. A., \& Hardy, A. (2009). A comparison of data sets varying in spatial accuracy used to predict the occurrence of wildlife-vehicle collisions. Environmental Management, 44, $268-277$. https://doi.org/10.1007/s00267-009-9303-y

Hothorn, T., Muller, J., Held, L., Most, L., \& Mysterud, A. (2015). Temporal patterns of deer-vehicle collisions consistent with deer activity pattern and density increase but not general accident risk. Accident Analysis \& Prevention, 81, $143-152$. https://doi.org/10.1016/j.aap.2015.04.037

International Business Publications. (2013). Lithuania investment, trade laws and regulations handbook. Strategic information and basic laws.

Kämmerle, J., Kroschel, M., Brieger, F., \& Hagen, R. (2017). Temporal patterns in road crossing behaviour in roe deer (Capreolus capreolus) at sites with wildlife warning reflectors. PLoS One, 12(9). https://doi.org/10.1371/journal.pone.0184761

Kušta, T., Keken, Z., Ježeka, M., Holá, M., \& Šmíd, P. (2016). The effect of traffic intensity and animal activity on probability of ungulate-vehicle collisions in the Czech Republic. Safety Science, 91, 105-113. https://doi.org/10.1016/j.ssci.2016.08.002

Lagos, L., Picos, J., \& Valero, E. (2012). Temporal pattern of wild ungulate-related traffic accidents in northwest Spain. European Journal of Wildlife Research, 58, 661-668. https://doi.org/10.1007/s10344-012-0614-6

Lamberti, P., Mauri, L., Merli, E., Dusi, S., \& Apollonio, M. (2006). Use of space and habitat selection by roe deer Capreolus capreolus in a Mediterranean coastal area: how does woods landscape affect home range? Japan Ethological Society, 24, 181188. https://doi.org/10.1007/s10164-005-0179-x

Langbein, J. (2007). National deer-vehicle collisions project: England 2003-2005 (Final Report to the Highways Agency). The Deer Initiative.

Langbein, J., Putman, R. J., \& Pokorny, B. (2011). Road traffic accidents involving ungulates and available measures for mitigation. In R. J. Putman, M. Apollonio, \& R. Andersen (Eds.), Ungulate management in Europe: problems and practices (pp. 215 259). Cambridge University Press.

Lithuanian Road Administration under the Ministry of Transport and Communications. (n.d). https://lakd.lrv.lt/en/

Madsen, A., Prang, A., \& Strandgaard, H. (2002). Factors causing traffic killings of roe deer Capreolus capreolus in Denmark. Wildlife Biology, 8, 55-61. https://doi.org/10.2981/wlb.2002.008

Mateos-Quesada, P., \& Carranza, J. (2000). Reproductive patterns of roe deer in Central Spain. Etología, 8, 17-20.

Morelle, K., Lehaire, F., \& Lejeune, P. (201). Spatio-temporal patterns of wildlife-vehicle collisions in a region with a high-density road network. Nature Conservation, 5, 53-73. https://doi.org/10.3897/natureconservation.5.4634

Oškinis, V., Ignatavičius, G., \& Vilutienè, V. (2013). An evaluation of wildlife-vehicle collision pattern and associated mitigation strategies in Lithuania. Environmental Engineering and Management, 12, 2323-2330. https://doi.org/10.30638/eemj.2013.284

Pokorny, B. (2006). Roe deer-vehicle collisions in Slovenia: situation, mitigation strategy and countermeasures. Veterinarski Arhiv, 76, $177-187$.

Putman, R. J. (1997). Deer and road traffic accidents: options for management. Journal of Environmental Management, 51 , $43-57$. https://doi.org/10.1006/jema.1997.0135

Richard, E., Morellet, N., Cargnelutti, B., Angibault, J. M., Vanpé, C., \& Hewison, A. J. M. (2008). Ranging behavior and excursions of female roe deer during the rut. Behavioural Processes, 79(1), 28-35. https://doi.org/10.1016/j.beproc.2008.04.008

Rodríguez-Morales, B., Díaz-Varela, E. R., \& Marey-Pérez, M. F. (2013). Spatiotemporal analysis of vehicle collisions involving wild boar and roe deer in NW Spain. Accident Analysis \& Prevention, 60, 121-133. https://doi.org/10.1016/j.aap.2013.07.032

Seiler, A. (2004). Trends and spatial patterns in ungulate-vehicle collisions in Sweden. Wildlife Biology, 10, $301-313$. https://doi.org/10.2981/wlb.2004.036 
Seiler, A. (2005). Predicting locations of moose-vehicle collisions in Sweden. Journal of Applied Ecology, 42, 371-382. https://doi.org/10.1111/j.1365-2664.2005.01013.x

Seiler, A., Mattias, O., Carme, R., \& Grift, E. (2016). SAFEROAD safe roads for wildlife and people: Cost-benefit analyses for wildlife and traffic safety (SAFEROAD Technical report No. 4). https://www.saferoad-cedr.org/upload_mm/4/d/1/2346434d206d-463e-a2ea-3136722a2e1f_CEDR\%20Call\%202013_SAFEROAD_Technical\%20Report\%204.pdf

Snow, N. P., Williams, D. M., \& Porter, W. F. (2014). A landscape-based approach for delineating hotspots of wildlife-vehicle collisions. Landscape Ecology, 29, 817-829. https://doi.org/10.1007/s10980-014-0018-y

Wahlström, L. K., \& Liberg, O. (1995). Patterns of dispersal and seasonal migration in roe deer (Capreolus capreolus). Journal of Zoology, 235, 455-467. https://doi.org/10.1111/j.1469-7998.1995.tb01762.x

\section{Notations}

DVCs - deer - vehicle collisions;

AVCs - animal - vehicle collisions;

UVCs - ungulate - vehicle collisions;

WVC - Wildlife vehicle collisions. 